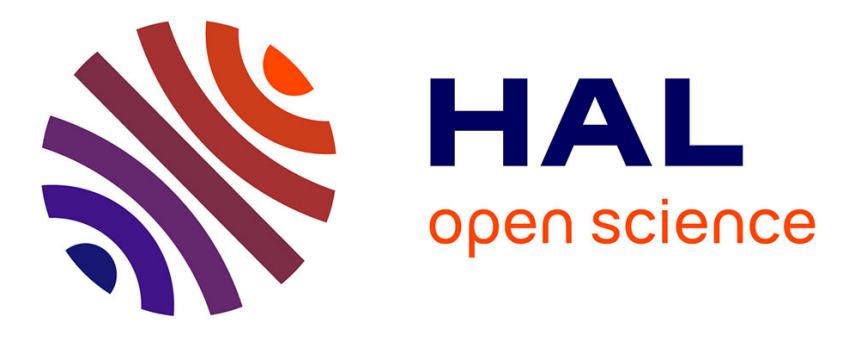

\title{
Design of Polarizing Cells for Broadband Reflectors
}

Samara Gharbieh, Maria Garcia-Vigueras, Renaud Loison, Ali Harmouch, Akil Jrad

\section{To cite this version:}

Samara Gharbieh, Maria Garcia-Vigueras, Renaud Loison, Ali Harmouch, Akil Jrad. Design of Polarizing Cells for Broadband Reflectors. 2019 IEEE International Symposium on Antennas and Propagation and USNC-URSI Radio Science Meeting, Jul 2019, Atlanta, GA, United States. 10.1109/APUSNCURSINRSM.2019.8889075 . hal-02166165v2

\section{HAL Id: hal-02166165 https://hal.science/hal-02166165v2}

Submitted on 13 Feb 2020

HAL is a multi-disciplinary open access archive for the deposit and dissemination of scientific research documents, whether they are published or not. The documents may come from teaching and research institutions in France or abroad, or from public or private research centers.
L'archive ouverte pluridisciplinaire HAL, est destinée au dépôt et à la diffusion de documents scientifiques de niveau recherche, publiés ou non, émanant des établissements d'enseignement et de recherche français ou étrangers, des laboratoires publics ou privés. 


\title{
Design of Polarizing Cells for Broadband Reflectors
}

\author{
Samara Gharbieh ${ }^{* \dagger}$, Maria García-Vigueras*, Renaud Loison*, Ali Harmouch ${ }^{\dagger}$ and Akil Jrad ${ }^{\ddagger}$ \\ ${ }^{*}$ Institute of Electronic and Telecommunication in Rennes, IETR, INSA Rennes \\ ${ }^{\dagger}$ CRSI, Lebanese University, Faculty of Engineering, EDST, Tripoli, Lebanon \\ ${ }^{\ddagger}$ LEPA, Lebanese University, Faculty of Sciences, EDST, Tripoli, Lebanon \\ Emails: samara.gharbieh@insa-rennes.fr, maria.garcia-vigueras@insa-rennes.fr, renaud.loison@insa-rennes.fr
}

\begin{abstract}
This paper presents the topology of two cells that can be used to conceive periodic polarizing reflectors. These reflectors are capable to convert a linearly polarized incident wave to a circularly polarized reflected one. Two polarizer designs are presented and their performance is validated through simulated results.
\end{abstract}

\section{INTRODUCTION}

Polarizers are fundamental elements in several communications and remote sensing applications [1]. Polarizing surfaces convert a linearly polarized (LP) wave into a circularly polarized one, thus allowing to replace $\mathrm{CP}$ radiators by simpler LP ones [2]. These surfaces can operate either in reflection [3] or in transmission [4], and they are usually made of metallic scatterers which are periodically arranged and printed on single or multiple layers of dielectric substrates [5], [6].

In this contribution, we are interested in conceiving periodic reflecting surfaces operating over a wide frequency range. Multiple works have been already reported in the literature aiming at this purpose. All proposals consider an LP source slanted by $45^{\circ}$ illuminating the structure, and three main design strategies can be identified. The first one is to use a scatterer including two perpendicular resonators [1], [7]. Both these resonators are excited by the impinging LP wave. The key point of this solution is the fact that the associated resonance frequencies are slightly shifted in frequency, thereby generating the desired $90^{\circ}$ phase difference between the two components, and therefore, a CP reflected field. Since this approach is based on a resonance phenomena, it normally operates only over a reduced bandwidth. The second strategy uses non-resonant patterns which behave as a capacitor or an inductor depending on the considered component of the incident electric field [3], [5]. Classical patterns presenting this behavior are meander lines. By properly tuning the values of such reactive components, $90^{\circ}$ phase shift can be obtained between the orthogonal components of the reflected field. By cascading various of these gratings, broadband CP conversion can be attained. The third strategy considers multilayer structures where each layer is in charge of interacting mainly with only one of the orthogonal components of the incident field [4], [6]. Wideband behavior can be again attained, since the considered scatterers are normally non resonant. However, multilayer dielectric structures are normally avoided in space applications. Our objective is therefore to attain broadband $\mathrm{CP}$ conversion employing only one PCB layer.

In this paper, two new designs of polarizing cells are presented, which are fundamentally based on the second

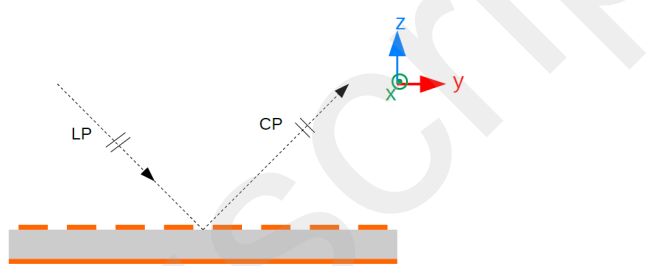

Fig. 1: Polarizing surface converts an LP wave into a CP one.

approach. The main contribution of this paper is that the two presented designs generalize the second approach to patterns other than the classical meander. This leads to cells which have a simple structure and can be printed on a single layer. Moreover, the designed cells have a good performance over a wider frequency band than the cells presented in the literature (for example the bandwith in [7] is $44 \%$ for an axial ratio smaller than $3 \mathrm{~dB}$ ). The paper is organized as follows. The operation principle is presented in Section II. In Section III, the cell design and simulation results are shown. A conclusion is given in Section IV.

\section{OPERATION PRINCIPLE}

The considered scenario is sketched in Fig. 1 consisting in a reflector which is built periodically from unit cells that are printed over a dielectric substrate and backed by a metallic ground plane.This reflector is illuminated by an LP plane wave which is tilted by $45^{\circ}$ with respect to the $x$ $y$ axis. This slanted field can be decomposed into two inphase components of equal amplitude aligned with the main axes. In order to convert the illuminating LP wave into a reflected $\mathrm{CP}$ wave, it is necessary to synthesize unit cells presenting $90^{\circ}$ phase shift between the reflection coefficients associated to $x$ and $y$ field components. We consider a lossless substrate with a thickness of $\lambda_{0} / 4$, where $\lambda_{0}$ is the wavelength at the central frequency. Thus, at this frequency, the value of the cell input impedance is purely imaginary and corresponds to the impedance of the scatterer in the unit cell. In order to design such scatterers, the main objective is to find patterns whose reflection coefficients along $x$ and $y$ are in phase quadrature. This objective can be achieved if the equivalent impedances follow the configurations sketched in Fig. 2. The case of Fig. 2a and Fig. 2c would correspond to classical meander lines, behaving either as capacitors or inductors. Additionally, cells behaving equally in both axes, either inductively (Fig. 2b) or capacitively (Fig. 2d), would also produce $\mathrm{CP}$. 


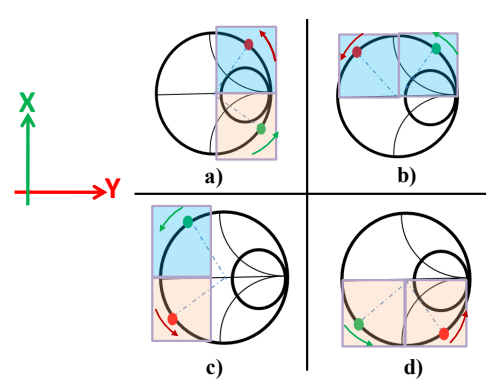

Fig. 2: Smith chart of reflection coefficients' phases.

\section{IMPLEMENTATION AND RESULTS}

The polarizers studied are periodic surfaces printed on a substrate with a ground plane underneath (Fig. 1). We consider ideal conditions without losses (the substrate is vacuum and the conductors are perfect). These conditions are chosen to validate the design strategy. For future studies, real substrates will be considered. The central operating frequency is 20 $\mathrm{GHz}$ and the periodicity is fixed to $P=\lambda_{0} / 3=5 \mathrm{~mm}$. This choice of periodicity is made to avoid the presence of grating lobes within the studied frequency band. The substrate thickness is set to be $\lambda_{0} / 4=3.75 \mathrm{~mm}$. Cells are tested on [10-35 GHz] in order to investigate their performance in polarization conversion over a wide frequency band. In the previous section, several possible cases are shown (Fig. 2) in order to add $90^{\circ}$ phase difference between the phases of the two components of the field. To demonstrate the feasibility of several polarizing patterns, we choose the two following configurations: i) The configuration of Fig. 2(c) where the pattern is inductive for the $X$ component and capacitive for the $Y$ component; and ii) The configuration of Fig. 2(d) where the pattern is capacitive for both polarizations. The two designed

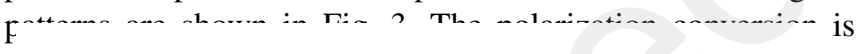

c

$\mathrm{s}$

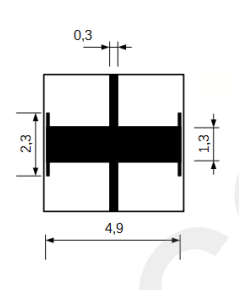

a)

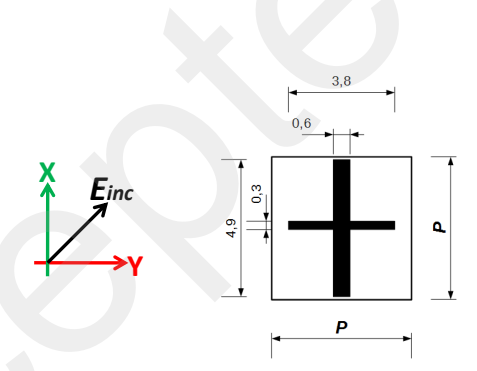

b)
Fig. 3: Designed cells (all the dimensions are in $\mathrm{mm}$.)

The designed cells are simulated in HFSS, under normal incidence and using infinite periodic boundary conditions. Fig. 4 shows the axial ratios corresponding to the cells of Fig. 3 (a) and (b) respectively. These graphs show that the designed cells are capable of converting an incoming linearly polarized wave to an outgoing circularly polarized wave over a wide frequency band for an axial ratio that is smaller than 2 $\mathrm{dB}(48.6 \%$ and $70.9 \%$ respectively). These simulation results validate our proposal, and encourage the use of the second cell for wider band applications.
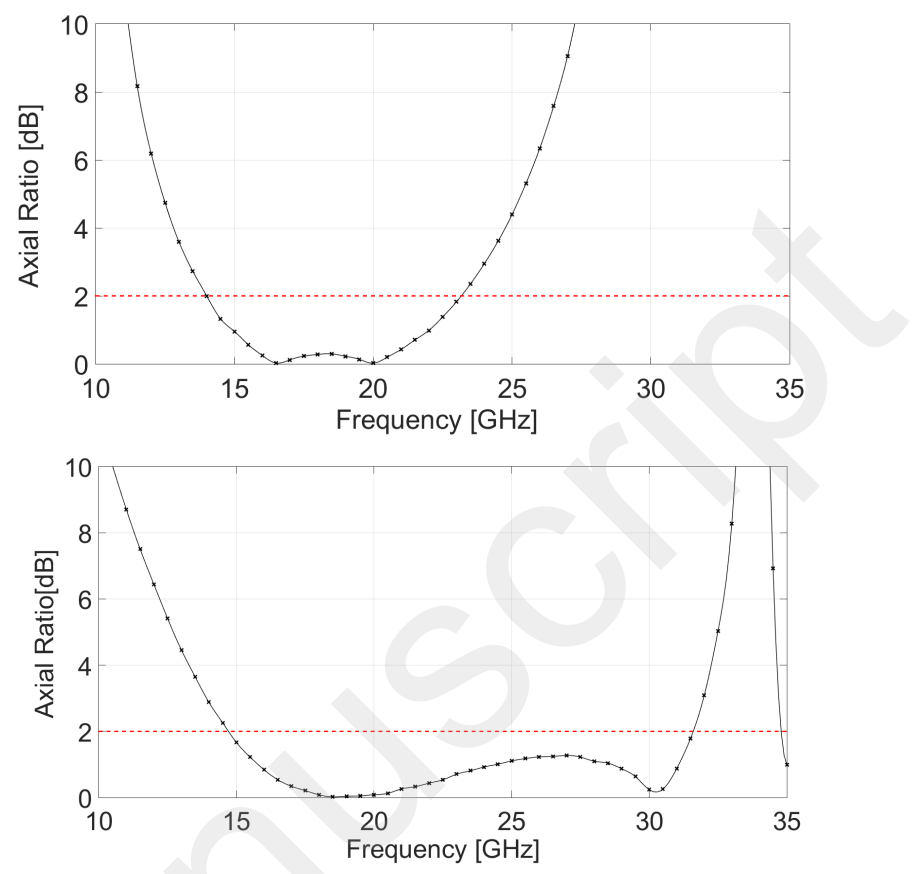

Fig. 4: Axial ratio variation with frequency for the cells in Fig. 3a and b, respectively.

\section{CONCLUSION}

In this paper, we presented two different cells for the conception of polarizing reflectors. These cells make it possible to convert the linear polarization of a wave into a circular one. They extend the principle of the meander polarizer by generating the phase shift of $90^{\circ}$ using capacitive or inductive behaviors along two main axes. The principle was validated by simulations and large bandwidths were obtained $(48.6 \%$ and $70.9 \%$ ). The extended version of this paper will present in more detail the design of the patterns and their performance depending on the angle of incidence.

\section{REFERENCES}

[1] M. Veysi, C. Guclu, O. Boyraz, and F. Capolino, "Infrared polarizing reflectarray metasurfaces," in Antennas and Propagation Society International Symposium (APSURSI), 2014 IEEE, pp. 1017-1018, IEEE, 2014.

[2] W. Tang, G. Goussetis, N. J. Fonseca, H. Legay, E. Sáenz, and P. de Maagt, "Coupled split-ring resonator circular polarization selective surface," IEEE Transactions on Antennas and Propagation, vol. 65, no. 9, pp. 4664-4675, 2017.

[3] C. Zhang, Y. Wang, F. Zhu, G. Wei, J. Li, C. Wu, S. Gao, and H. Liu, "A planar integrated folded reflectarray antenna with circular polarization," IEEE Transactions on Antennas and Propagation, vol. 65, no. 1, pp. 385390, 2017.

[4] C. Pfeiffer and A. Grbic, "Millimeter-wave transmitarrays for wavefront and polarization control," IEEE Transactions on Microwave Theory and Techniques, vol. 61, no. 12, pp. 4407-4417, 2013.

[5] W. Tang, S. Mercader-Pellicer, G. Goussetis, H. Legay, and N. J. Fonseca, "Low-profile compact dual-band unit cell for polarizing surfaces operating in orthogonal polarizations," IEEE Transactions on Antennas and Propagation, vol. 65, no. 3, pp. 1472-1477, 2017.

[6] M. Hosseini and S. V. Hum, "A circuit-driven design methodology for a circular polarizer based on modified jerusalem cross grids," IEEE Transactions on Antennas and Propagation, vol. 65, no. 10, pp. 5322 5331, 2017.

[7] R. Orr, G. Goussetis, V. Fusco, and E. Saenz, "Linear-to-circular polarization reflector with transmission band," IEEE Transactions on Antennas and Propagation, vol. 63, no. 5, pp. 1949-1956, 2015. 